\title{
Assessment of Interdiffusion Coefficient Through Spreadsheet Implementation
}

\author{
Oscar Marcelo Suarez $\left({ }^{\dagger}\right)$, Susan E. Babcock $\left({ }^{(}\right)$ \\ Dept. of Materials Science and Engineering \\ University of Wisconsin - Madison \\ 1509 University Ave. \\ Madison, WI 53706
}

\begin{abstract}
In intermediate materials science laboratory courses the analysis of experimental data is heavily dependent on the students' proficiency in the use of commercial softwares. In such courses, the students are required to apply theoretical principles and analyze the corresponding experimental results. In the present article, a spreadsheet implementation results in a simplified alternative to analyze experimental data when numerical techniques are required. Numerical integration and differentiation are performed by using Microsoft Excel ${ }^{\mathrm{TM}} 7.0$ for Windows. Finally the resulting analysis is contrasted against literature data and important conclusions are drawn.
\end{abstract}

\section{Introduction}

Cookbook-type of data analysis can help those students with less computer skills catch up with the rest of the class and comply with the requirements of the course. However, when dealing with mathematical problems that cookbook approach can hinder the understanding of the physical or chemical principles on which the analysis is based $\left({ }^{1}\right)$. In addition the application of numerical analysis techniques and their limitations may not be evident if no breakdown of the problem mechanics is provided. As a worthy example of an alternative approach, the study of chemical diffusion in the copper-nickel binary system is presented as set up in a college Physical Metallurgy laboratory course offered at the Dept. of Materials Science and Engineering of the University of Wisconsin-Madison every Spring semester. As prerequisite for this laboratory there is an introductory Phase Transformation course. Therefore the students are supposed to be familiar with the phenomenological viewpoint of chemical diffusion in a metallic system. In addition, some knowledge of numerical analysis is beneficial for the complete understanding of the present experiment.

\section{Basics of Diffusion and Matano-Boltzmann's Analysis}

Diffusion in an A-B substitutional metallic system comprises the analysis of atom mobility as affected by temperature and chemical potential differences across an interface (Figure 1). In this case the non-steady diffusion process is described by Fick's Second Law:

\footnotetext{
${ }^{\dagger}$ Teaching Assistant

* Associate Professor
} 


$$
\frac{\partial \mathrm{c}}{\partial \mathrm{t}}=\nabla(\tilde{\mathrm{D}} \nabla \mathrm{c})
$$

eq. 1

which is reduced to: $\frac{\partial \mathrm{c}}{\partial \mathrm{t}}=\frac{\partial}{\partial \mathrm{x}}\left(\tilde{\mathrm{D}} \frac{\partial \mathrm{c}}{\partial \mathrm{x}}\right)$

eq. 2

for a one-dimensional problem in a binary system, e. g. copper-nickel.

c: atomic chemical concentration of specimen $\mathrm{A}$ in $\mathrm{B}$ at a given $\mathrm{x}$.

$\mathrm{x}$ : diffusing distance.

$\widetilde{\mathrm{D}}$ : interdiffusion coefficient; in general $\widetilde{\mathrm{D}} \neq$ constant but $\widetilde{\mathrm{D}}=\widetilde{\mathrm{D}}(\mathrm{c})$.

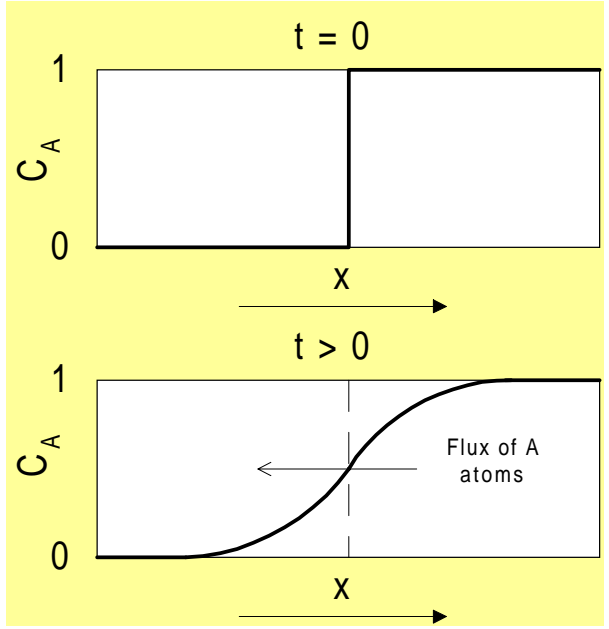

Figure 1: Schematic of the distribution profile at different annealing times for a diffusion couple composed by A (right) and B (right) metals slabs.

When $\widetilde{\mathrm{D}}$ depends on the concentration of $\mathrm{A}$, the differential equation 2 can be solved by means of the Matano-Boltzmann analysis $\left(^{2}\right)$. This approach requires the definition of a plane where $\mathrm{x}=\mathrm{x}_{\mathrm{M}}$ and for which the following equality verifies:

$$
\int_{0}^{\ell} \mathrm{x}^{\prime} \mathrm{dc}=0
$$

being $\mathrm{x}^{\prime}=\mathrm{x}-\mathrm{x}_{\mathrm{M}}$ and:

$\mathrm{x}_{\mathrm{M}}$ : position of the Matano interface.

$\ell$ : maximum distance in the diffusion couple.

Clearly, equation 3 represents mass preservation: all atoms A who migrated from $x^{\prime}<0$ should accumulate on the other side of the interface $\left(x^{\prime}>0\right)$. Finally, after transforming the spatial variable, the solution for the unidimensional expression of Fick's Second Law is:

$$
\widetilde{\mathrm{D}}\left(\mathrm{c}^{*}\right)=-\left.\frac{1}{2 \mathrm{t}} \cdot \frac{\mathrm{dx}}{\mathrm{dc}}\right|_{\mathrm{C}^{*}} \cdot \int_{0}^{\mathrm{C}^{*}} \mathrm{x} \mathrm{dc} \quad \text { eq. } 4
$$


While this equation can be numerically solved by a number of commercial mathematical softwares, a spreadsheet computation was implemented because of its versatility as indicated in the next sections.

\section{Experimental Setup}

In order to analyze the diffusion in substitutional alloys, the $\mathrm{Cu}-\mathrm{Ni}$ system was selected. The corresponding equilibrium phase diagram is showed in Figure $2\left({ }^{3}\right)$. A diffusion couple was prepared with high purity slabs of $\mathrm{Cu}$ and $\mathrm{Ni}$ and heat treated at $950^{\circ} \mathrm{C}(1223 \mathrm{~K})$ under vacuum for 95 hours and subsequently quenched.

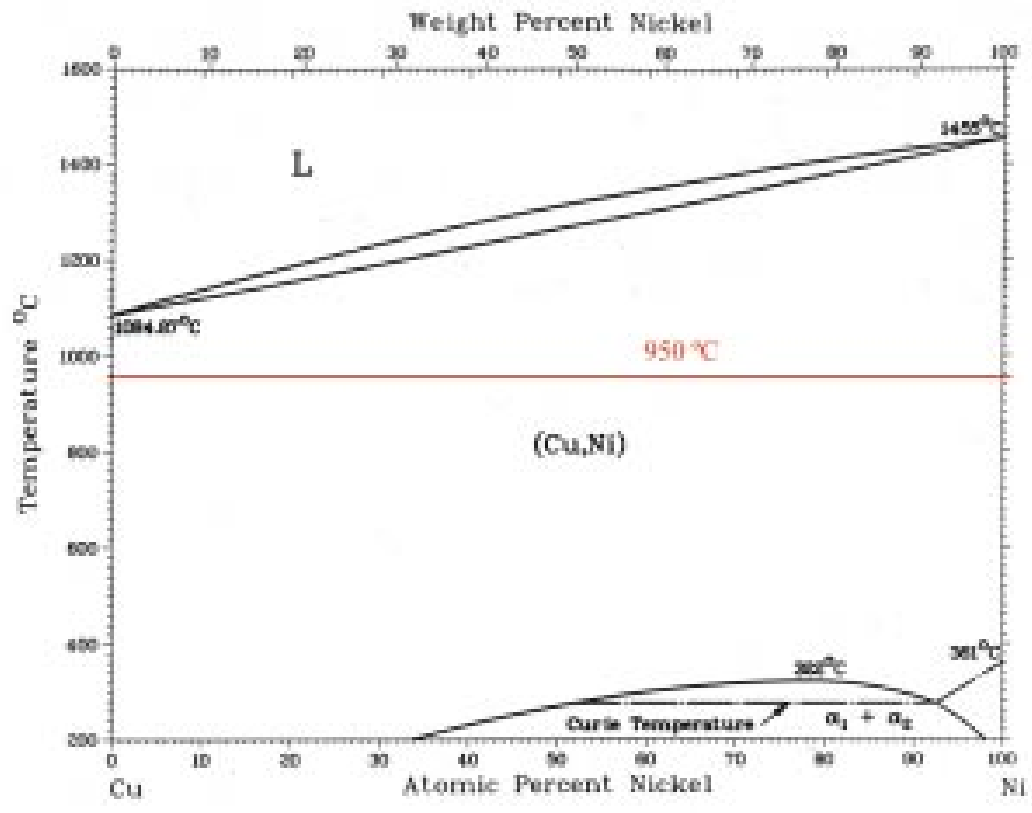

Figure 2: Copper-Nickel equilibrium phase diagram indicating the annealing temperature for the present experiment.

The specimen was cut perpendicularly to the diffusion interface and observed in a secondary electron microscope SEM by the students. While the SEM operating voltage was $20 \mathrm{kV}$, a $1 \mathrm{~mm}$ aperture was selected. An Energy-Dispersive Spectrometry EDS analyzer allowed for the fast examination of the diffusion profile printout in Figure 3 via a linescan option. After discussing this preliminary results the students designed a strategy for the number of data points and its distribution along a straight line perpendicular to the interface. As a result 40 EDS microanalysis data points were obtained for the studied specimen; the resulting profile is indicated in Figure 4. In Table 1, the corresponding raw data are given. 


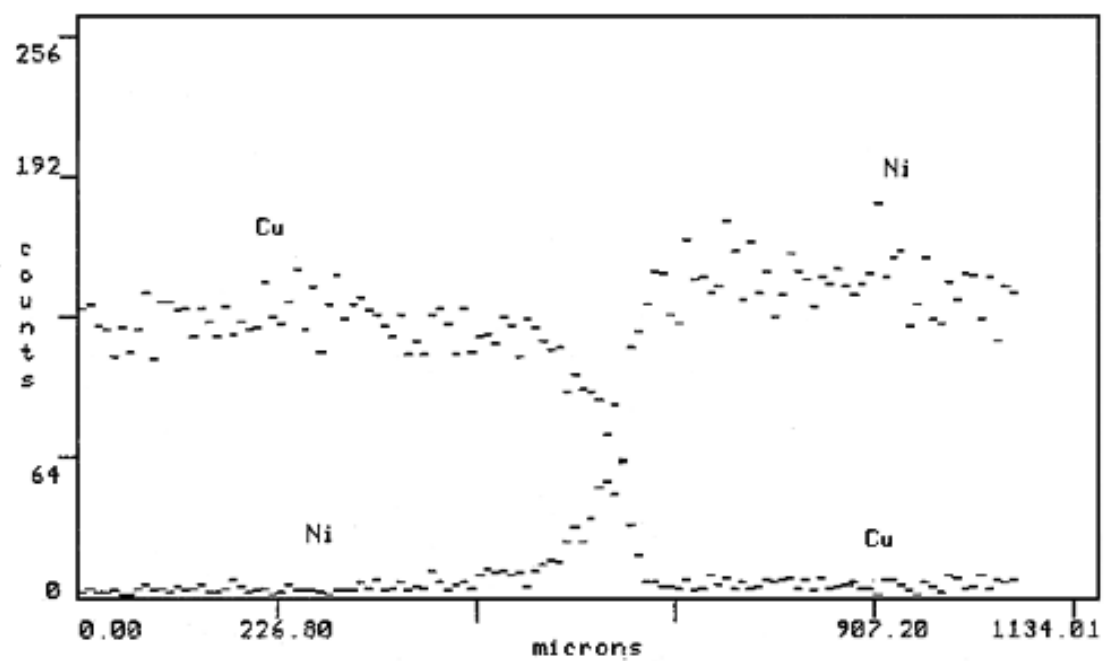

Figure 3: Draft of the linescan obtained in the EDS analyzer with only 1 second dwelling time at each microanalyzed spot.

\begin{tabular}{||c|c|c||}
\hline Position [cm] & Cu (at. conc.) & Ni (at. conc.) \\
\hline 0 & 0 & 1 \\
0.01001 & 0 & 1 \\
0.010954 & 0 & 1 \\
0.012274 & 0.0323 & 0.9677 \\
0.013104 & 0.2723 & 0.7277 \\
0.014237 & 0.4392 & 0.5608 \\
0.015149 & 0.6502 & 0.3498 \\
0.016238 & 0.6631 & 0.3369 \\
0.01726 & 0.7315 & 0.2685 \\
0.018392 & 0.7873 & 0.2127 \\
0.019222 & 0.8066 & 0.1934 \\
0.020242 & 0.8464 & 0.1536 \\
0.021223 & 0.8626 & 0.1374 \\
0.022356 & 0.8845 & 0.1155 \\
0.023377 & 0.8862 & 0.1138 \\
0.024358 & 0.9125 & 0.0875 \\
0.025491 & 0.9064 & 0.0936 \\
0.02636 & 0.9173 & 0.0827 \\
0.027384 & 0.9273 & 0.0727 \\
0.028363 & 0.9434 & 0.0566 \\
0.030325 & 0.9489 & 0.0511 \\
0.032064 & 0.9622 & 0.0378 \\
0.033915 & 0.968 & 0.032 \\
0.035725 & 0.9717 & 0.0283 \\
0.037312 & 0.9906 & 0.0094 \\
0.039162 & 0.9917 & 0.0083 \\
0.041013 & 0.9918 & 0.0082 \\
0.042601 & 0.9954 & 0.0046 \\
0.044757 & 0.9953 & 0.0047 \\
0.048719 & 1 & 0 \\
\hline
\end{tabular}

Table 1: Raw data set as obtained by EDS analysis 


\section{Data Analysis}

In the discerning study that follows, only $\widetilde{\mathrm{D}}$ as a function of one of the diffusing species - in this case, copper - has been considered for the sake of conciseness. Nonetheless, the proposed educational method is applicable to both diffusion couple components.

\subsection{Preparation of the Data Set}

To solve Fick's second law, the variable $\mathrm{x}$ needs to be transformed into $\mathrm{x}^{\prime}=\mathrm{x}-\mathrm{x}_{\mathrm{M}}$ where the $\mathrm{x}_{\mathrm{M}}$ is the position of the Matano interface that needs to be determined. Unfortunately, the raw data cannot be used as such since both its dispersion and the small number of data points would introduce a larger scattering of the results. Therefore the instructor should preprocess the data so as to generate a curve that fits the data set. In the present case such preprocessing was performed using Statistica $^{\mathrm{TM}}$, a statistical package provided with a non-linear regression module. It was found that the most appropriate function that fits our data was:

$$
\mathrm{x}=\mathrm{a} \cdot \tan \left(\mathrm{b}+\mathrm{c}_{\mathrm{Cu}}\right)+\mathrm{d} \cdot e^{\mathrm{f} \cdot \mathrm{c}_{\mathrm{cu}}}+\mathrm{x}_{0} \quad \text { eq. } 5
$$

where:

$\mathrm{a}, \mathrm{b}, \mathrm{d}, \mathrm{f}$ and $\mathrm{x}_{\mathrm{o}}$ are statistical parameters

$e$ is the base of the neperian logarithms

$\mathrm{x}$ is the distance in $\mathrm{cm}$

and $\mathrm{c}_{\mathrm{cu}}$ is the atomic concentration of copper at each position $\mathrm{x}$.

The estimated statistical parameters are given in Table 2.

\begin{tabular}{|ccccc||}
\hline $\mathrm{a}$ & $\mathrm{b}$ & $\mathrm{d}$ & $\mathrm{f}$ & $\mathrm{x}_{0}$ \\
\hline 0.002041 & 0.511728 & -0.005368 & -106.808 & 0.011210 \\
\hline
\end{tabular}

Table 2: Non-linear regression parameters for equation 5 estimated by the least-squares method.

For the statistical model in equation 5 the computed correlation coefficient was very high:

$\mathrm{R}=0.98600$. In Figure 4 these fitted values are displayed along with the observed data points; the high correlation between fitted and observed values is apparent. For the remainder computations a new larger set with fitted values will replace the raw data set. In this case 101 fitted values of $x$ were calculated by means of eq. 5 at intervals of 0.01 molar fraction of copper. As mentioned before, this larger set assures a much smaller dispersion in the results. 


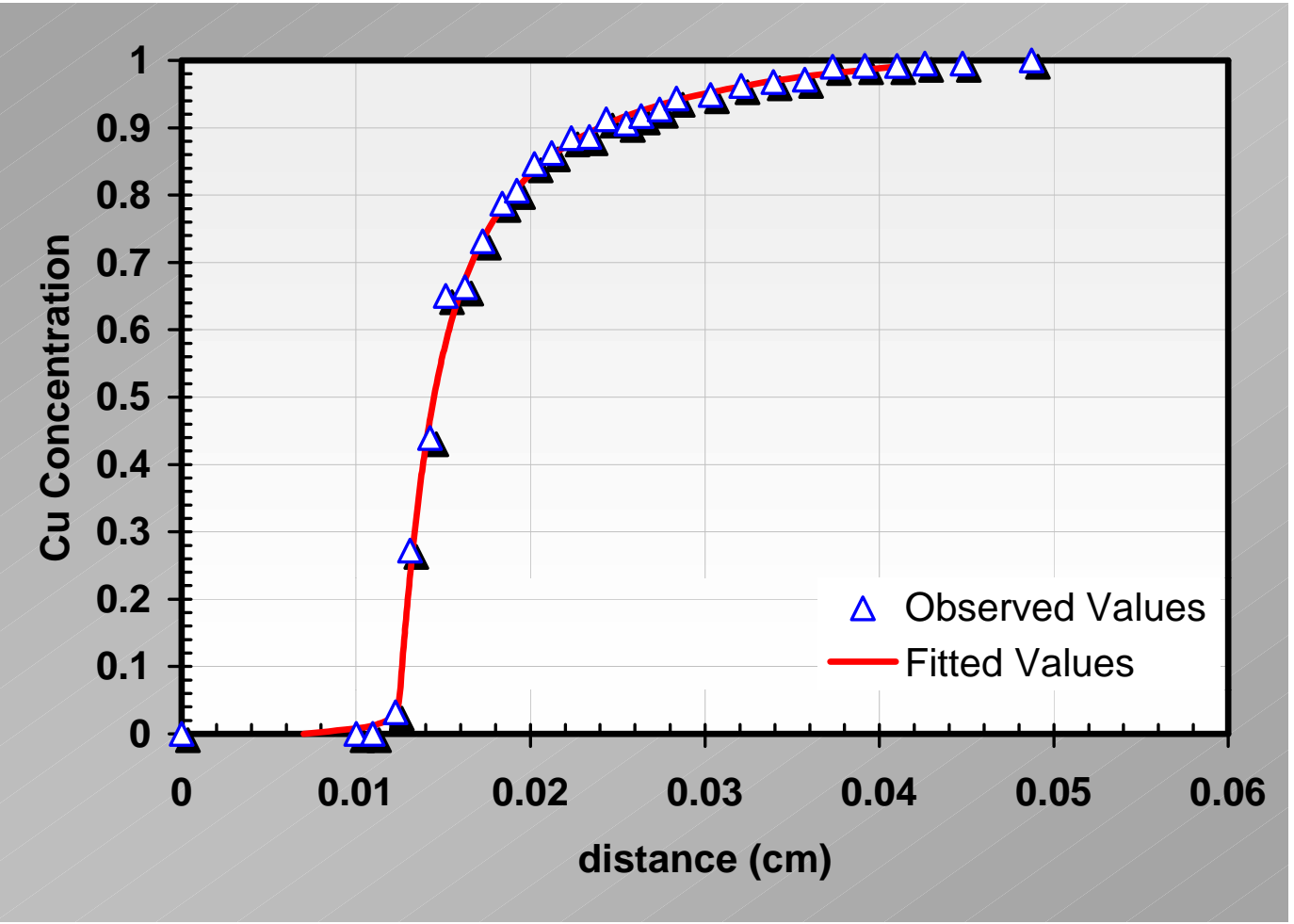

Figure 4: $\mathrm{Cu}$ concentration profile as determined by EDS analysis and its corresponding fitted curve as evaluated in Section 3.1.

\subsection{Estimation of the Matano Interface Position}

In Figure 5, the strategy used for calculating the position of this interface is illustrated. A forward numerical integration is performed from the origin $(\mathrm{x}=0)$ to a generic position $\mathrm{x}_{\mathrm{i}}$ to obtain $\mathrm{A}_{\mathrm{i}}$.

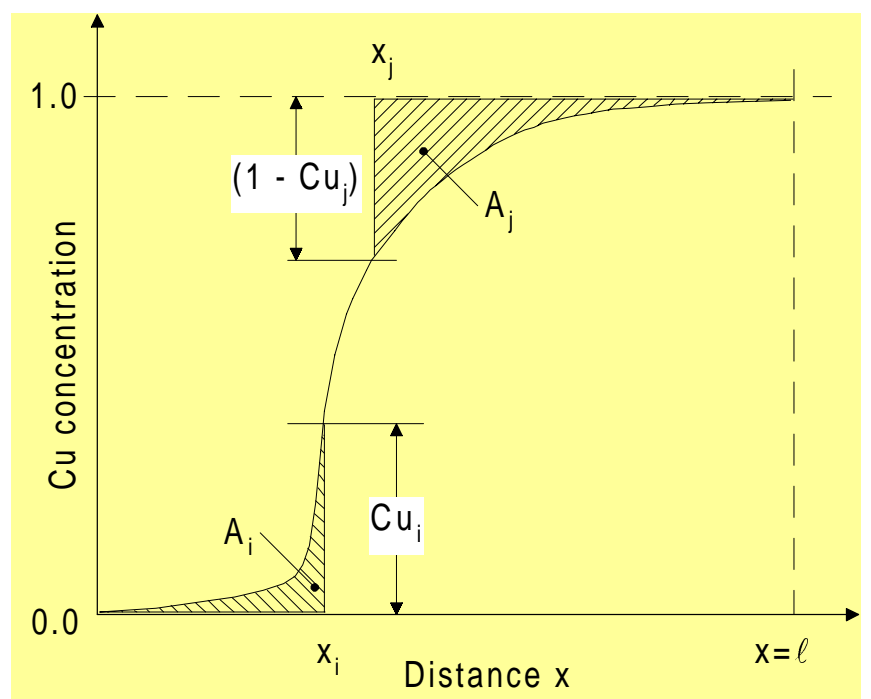

Figure 5: Scheme demonstrating how the areas $A_{i}$ and $\mathrm{A}_{\mathrm{j}}$ are successively calculated. 
This integral can be solved numerically by applying the trapezoidal approximation $\left({ }^{4,5}\right)$ as follows:

$$
\mathrm{A}_{\mathrm{i}}\left(\mathrm{x}_{\mathrm{i}}\right)=\int_{0}^{\mathrm{x}_{\mathrm{i}}} \mathrm{x} \mathrm{dc} \approx \sum_{\mathrm{k}=2}^{\mathrm{i}}\left(\mathrm{x}_{\mathrm{k}+1}-\mathrm{x}_{\mathrm{k}}\right) \cdot \frac{\left(\mathrm{c}_{\mathrm{k}+1}+\mathrm{c}_{\mathrm{k}}\right)}{2} \quad \text { eq. } 6
$$

Clearly this method approximates the area under the curve representing the function $c=f(x)$ to a series of trapezoids with individual areas:

$$
\left(\mathrm{x}_{\mathrm{k}+1}-\mathrm{x}_{\mathrm{k}}\right) \cdot \frac{\left(\mathrm{c}_{\mathrm{k}+1}+\mathrm{c}_{\mathrm{k}}\right)}{2}
$$

In Figure 6, an Excel spreadsheet is sketched where in cell F18 the formula representing equation 6 is showed. Note that the first value assigned to $A_{i}$, i.e. $A_{1}$ in cell F2, is equal to 0 .

\begin{tabular}{|c|c|c|c|}
\hline & $\mathbf{D}$ & $\mathbf{E}$ & $\mathbf{F}$ \\
\hline $\mathbf{1}$ & $\left.\mathbf{x}_{\mathbf{i}} \mathbf{( c m}\right)$ & $\mathbf{C u}_{\mathbf{i}}$ & $\mathbf{A}_{\mathbf{i}} \mathbf{( c m )}$ \\
\hline $\mathbf{2}$ & 0.00000 & 0.00000 & 0 \\
\hline$\ldots$ & $\ldots$ & $\ldots$ & $\ldots$ \\
\hline $\mathbf{1 6}$ & $\mathrm{D} 16$ & $\mathrm{E} 16$ & $\mathrm{~F} 16$ \\
\hline $\mathbf{1 7}$ & $\mathrm{D} 17$ & $\mathrm{E} 17$ & $\mathrm{~F} 17$ \\
\hline $\mathbf{1 8}$ & $\mathrm{D} 18$ & $\mathrm{E} 18$ & $=(\mathrm{E} 18+\mathrm{E} 17) / 2^{\star}(\mathrm{D} 18-\mathrm{D} 17)+\mathrm{F} 17$ \\
\hline $\mathbf{1 9}$ & $\mathrm{D} 19$ & $\mathrm{E} 19$ & $\mathrm{~F} 19$ \\
\hline $\mathbf{2 0}$ & $\mathrm{D} 20$ & $\mathrm{E} 20$ & $\mathrm{~F} 20$ \\
\hline
\end{tabular}

Figure 6: Spreadsheet schematic used to calculate the areas $A_{i}$.

Similarly a backward integration from the last data point $(\mathrm{x}=\ell)$ is carried out to obtain the shaded area $\mathrm{A}_{\mathrm{j}}$; in this case the integral can be described by:

$$
A_{j}\left(x_{j}\right)=\int_{x_{j}}^{\ell}(1-x) d c \approx \sum_{k=n-1}^{j}\left(x_{k+1}-x_{k}\right) \cdot\left(\frac{\left[\left(1-c_{k+1}\right)+\left(1-c_{k}\right)\right]}{2}\right) \quad \text { eq. } 7
$$

The corresponding formula is implemented in cell G99 of the spreadsheet sketched in Figure 7. Note that the last data point is in cells D101 and E101, and that G101 was equaled to zero.

\begin{tabular}{|c|c|c|c|c|}
\hline & $\mathbf{D}$ & $\mathbf{E}$ & $\mathbf{F}$ & $\mathbf{G}$ \\
\hline $\mathbf{1}$ & $\mathbf{x}_{\mathbf{i}}(\mathbf{c m})$ & $\mathbf{C u}_{\mathbf{i}}$ & $\left.\mathbf{A}_{\mathbf{i}} \mathbf{( c m}\right)$ & $\mathbf{A}_{\mathbf{i}}(\mathbf{c m})$ \\
\hline $\mathbf{2}$ & $\ldots$ & $\ldots$ & $\ldots$ & $\ldots$ \\
\hline $\mathbf{9 7}$ & $\mathrm{D} 97$ & $\mathrm{E} 97$ & $\ldots$ & $\mathrm{G} 97$ \\
\hline $\mathbf{9 8}$ & $\mathrm{D} 98$ & $\mathrm{E} 98$ & $\mathrm{~F} 98$ & $\mathrm{G} 98$ \\
\hline $\mathbf{9 9}$ & $\mathrm{D} 99$ & $\mathrm{E} 99$ & $\mathrm{~F} 99$ & $=\left((1-\mathrm{E} 99)+(1-\mathrm{E} 100) / 2^{*}(\mathrm{D} 100-\right.$ \\
& & & & $\mathrm{D} 99)+\mathrm{G} 100$ \\
\hline $\mathbf{1 0 0}$ & $\mathrm{D} 100$ & $\mathrm{E} 100$ & $\mathrm{~F} 100$ & $\mathrm{G} 100$ \\
\hline $\mathbf{1 0 1}$ & $\mathrm{X}=\ell$ & 1.0000 & $\mathrm{~F} 101$ & 0 \\
\hline
\end{tabular}

Figure 7: Spreadsheet schematic used to calculate the areas $A_{j}$.

Hence the Matano interface is where: $A_{i}=A_{j}$, i.e. the shaded areas in Figure 5 are equal when $\mathrm{x}=\mathrm{x}_{\mathrm{M}}$. After this procedure, it should expected that the students realize that equation 3 is 
another expression of mass preservation. In Figure 8, both areas $A_{i}$ and $A_{j}$ are plotted $v s$. the distance $\mathrm{x}$. An arrow indicates the intersection point, that is the position of the Matano interface.

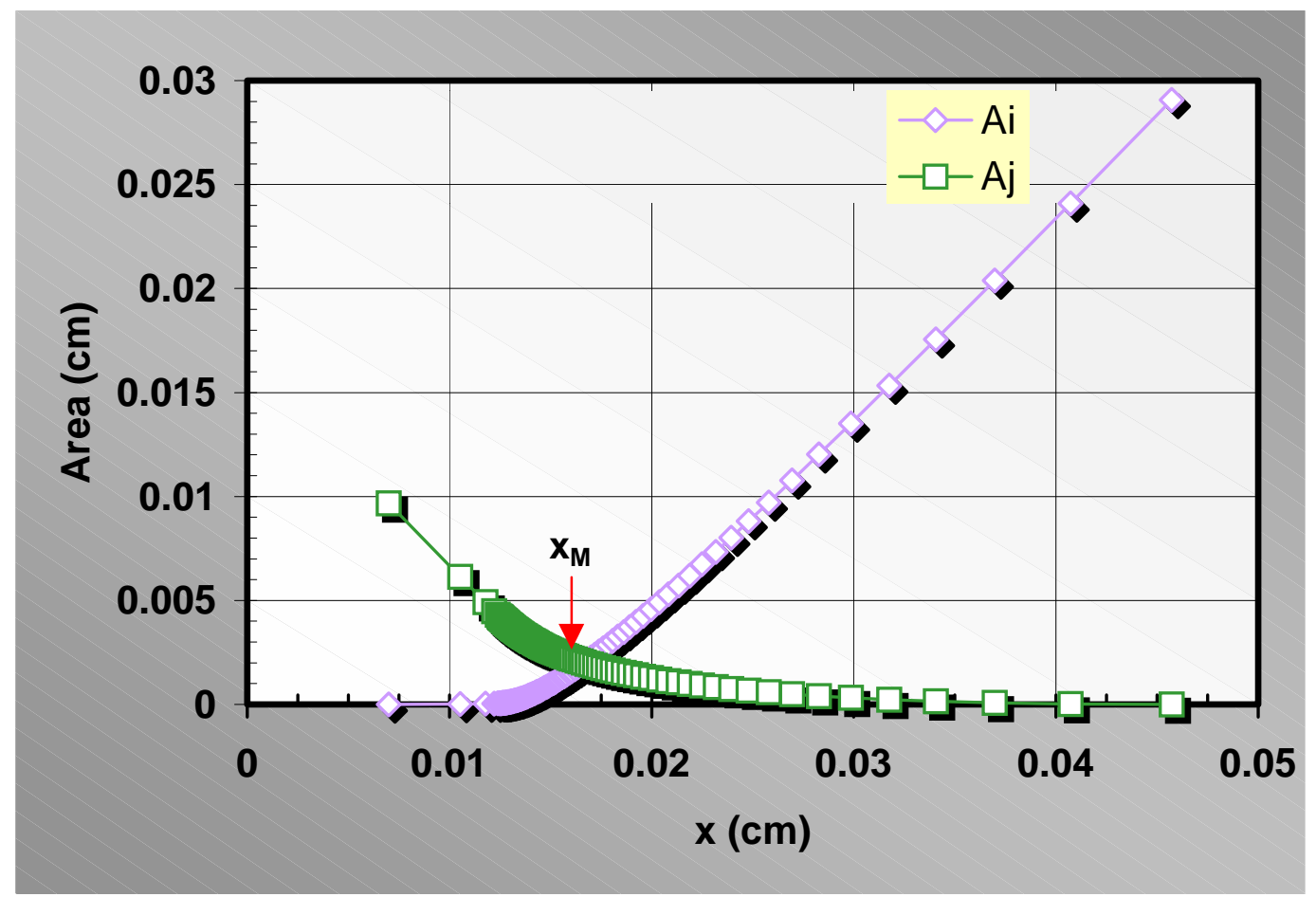

Figure 8: Plot of the estimated areas $A_{i}$ and $A_{j}$ as function of the distance $x$. The Matano interface, i. e. the intersection between both curves is indicated as $\mathrm{x}_{\mathrm{M}}$.

Through a linear interpolation displayed in Figure 9 this interface is computed as:

$$
\mathrm{x}_{\mathrm{M}}=\mathrm{x}_{\mathrm{M}-1}+\left(\mathrm{A}_{\mathrm{c}}-\mathrm{A}_{\mathrm{a}}\right) \cdot \frac{\left(\mathrm{x}_{\mathrm{M}+1}-\mathrm{x}_{\mathrm{M}-1}\right)}{\left(\mathrm{A}_{\mathrm{c}}-\mathrm{A}_{\mathrm{a}}\right)+\left(\mathrm{A}_{\mathrm{b}}-\mathrm{A}_{\mathrm{d}}\right)} \quad \text { eq. } 8
$$

In the present case this interface was estimated as: $\mathrm{x}_{\mathrm{M}}=0.016655 \mathrm{~cm}$.

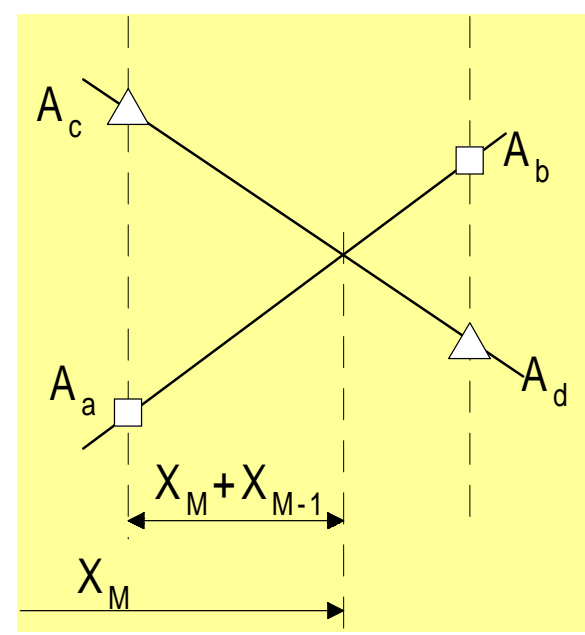

Figure 9: Schematic of the linear interpolation used to estimate the value of $x_{M}$ corresponding to the intersection between the curves $A_{i}$ (ascending) and $A_{j}$ (descending). 


\subsection{Estimation of $\mathrm{Cu}-\mathrm{Ni}$ Interdiffusion Coefficient}

With that value of $\mathrm{x}_{M}$ the transformed variable $\mathrm{x}^{\prime}$ is calculated as: $\mathrm{x}^{\prime}=\mathrm{x}-\mathrm{x}_{\mathrm{M}}$. This new variable is then plotted against the molar fraction of copper in Figure 10 in order to work on the terms involved in equation 4 . In this equation, the derivative factor is calculated separately by the three-point formula $\left({ }^{6}\right)$ or central difference formula $\left({ }^{7}\right)$. In brief, it consists of averaging the slopes of the secants behind and ahead of the point where the derivative is approximated (see Figure 7.1 in Ref. 7). Therefore the slope at $\mathrm{c}=\mathrm{c}^{*}$ is estimated as:

$$
\mathrm{s}\left(\mathrm{c}^{*}\right)=\left.\frac{\mathrm{dx}}{\mathrm{dc}}\right|_{\mathrm{C}^{*}} \approx \frac{1}{2} \cdot\left[\left(\frac{\mathrm{x}_{\mathrm{i}}^{\prime}-\mathrm{x}_{\mathrm{i}-1}^{\prime}}{\mathrm{c}_{\mathrm{i}}-\mathrm{c}_{\mathrm{i}-1}}\right)+\left(\frac{\mathrm{x}_{\mathrm{i}+1}^{\prime}-\mathrm{x}_{\mathrm{i}}^{\prime}}{\mathrm{c}_{\mathrm{i}+1}-\mathrm{c}_{\mathrm{i}}}\right)\right]_{\mathrm{c}_{\mathrm{i}}=\mathrm{c}^{*}} \text { eq. } 9
$$

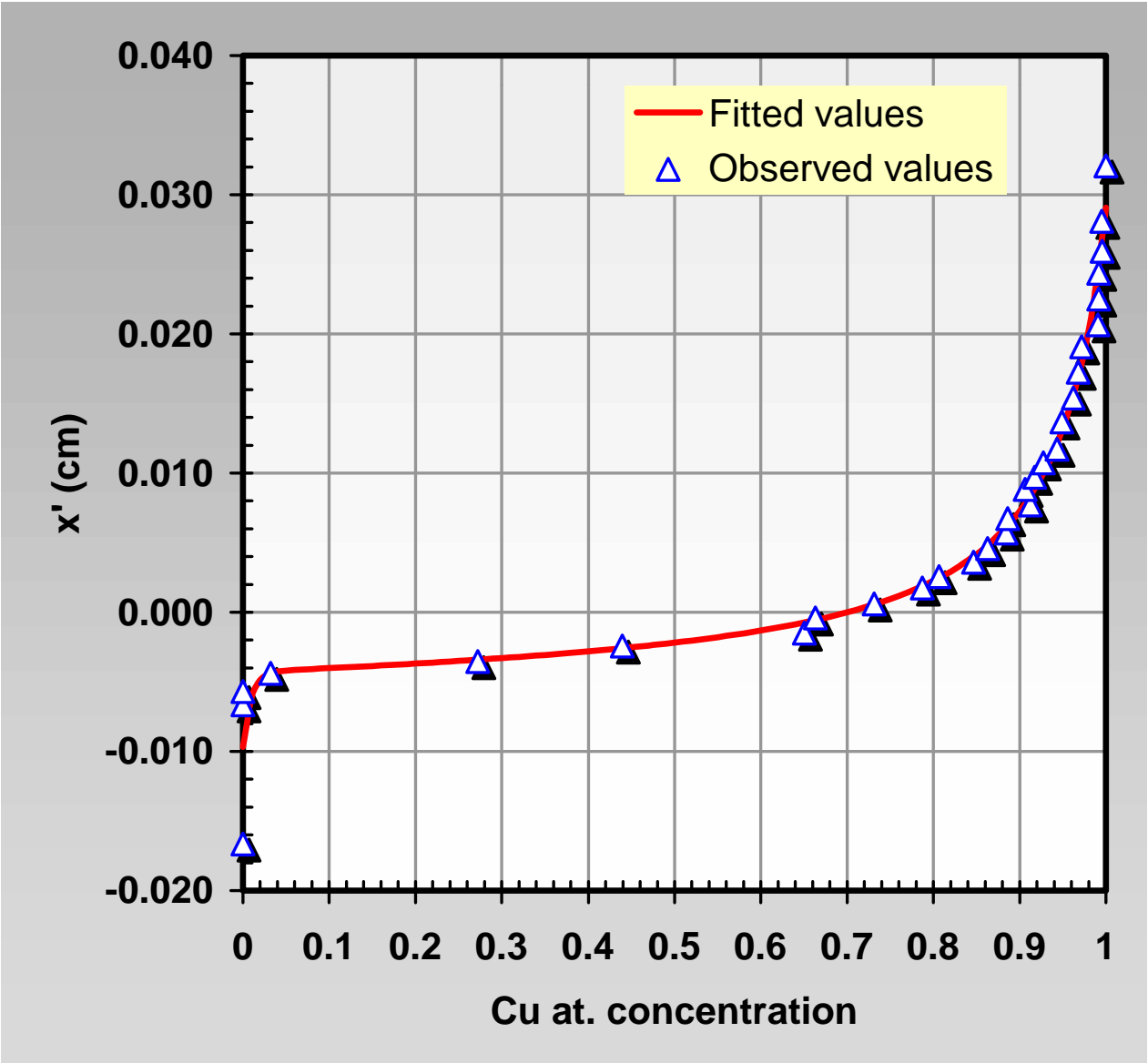

Figure 10: Plot the transformed variable $\mathrm{x}^{\prime}$ as a function of $\mathrm{Cu}$ concentration.

In Figure 11, the derivatives are computed in column I whereas cell I18 displays equation 9 as it was typed in.

On the other hand, the integral factor in equation 4 can be estimated by means of the trapezoid rule in a similar manner as for the calculation of areas $A_{i}$ and $A_{j}$ discussed in section 3.2. 


$$
\mathrm{I}\left(\mathrm{c}^{*}\right)=\int_{0}^{\mathrm{C}^{*}} \mathrm{x}^{\prime} \mathrm{dc} \approx \sum_{\mathrm{i}=2}^{\mathrm{m}} \frac{\left(\mathrm{x}_{\mathrm{i}}^{\prime}+\mathrm{x}_{\mathrm{i}-1}^{\prime}\right)}{2} \cdot\left(\mathrm{c}_{\mathrm{i}}-\mathrm{c}_{\mathrm{i}-1}\right)
$$

\begin{tabular}{|c|c|c|c|}
\hline & $\mathbf{G}$ & $\mathbf{H}$ & $\mathbf{I}$ \\
\hline $\mathbf{1}$ & $\mathbf{C u}_{\mathbf{i}}$ & $\mathbf{x}_{\mathbf{i}}$ & Derivative \\
\hline$\ldots$ & $\ldots$ & $\ldots$ & $\ldots$ \\
\hline $\mathbf{1 6}$ & $\mathrm{G} 16$ & $\mathrm{H} 16$ & $\mathrm{I} 16$ \\
\hline $\mathbf{1 7}$ & $\mathrm{G} 17$ & $\mathrm{H} 17$ & $\mathrm{I}$ \\
\hline $\mathbf{1 8}$ & $\mathrm{G} 18$ & $\mathrm{H} 18$ & $\begin{array}{c}=1 / 2^{*}((\mathrm{H} 18-\mathrm{H} 17) /(\mathrm{G} 18-\mathrm{G} 17) \\
+(\mathrm{H} 19-\mathrm{H} 18) /(\mathrm{G} 19-\mathrm{G} 18))\end{array}$ \\
\hline $\mathbf{1 9}$ & $\mathrm{G} 19$ & $\mathrm{H} 19$ & $\mathrm{I} 9$ \\
\hline $\mathbf{2 0}$ & $\mathbf{G} 20$ & $\mathrm{H} 20$ & $\mathrm{I} 20$ \\
\hline
\end{tabular}

Figure 11: Spreadsheet schematic used to estimate the derivative s(c*) in equation 9.

This equation is implemented in cell J18 of the spreadsheet sketched in Figure 12; column J contains the values of the sequential integrals.

\begin{tabular}{|c|c|c|c|c|}
\hline & $\mathbf{G}$ & $\mathbf{H}$ & $\mathbf{I}$ & $\mathbf{J}$ \\
\hline $\mathbf{1}$ & $\mathbf{C u}_{\mathbf{i}}$ & $\mathbf{x}_{\mathbf{i}}$ & Derivative & $\ldots$ \\
\hline $\boldsymbol{\ldots}$ & $\ldots$ & $\ldots$ & $\ldots$ & $\mathrm{J} 16$ \\
\hline $\mathbf{1 6}$ & $\mathrm{G} 16$ & $\mathrm{H} 16$ & $\mathrm{I} 16$ & $\mathrm{~J} 17$ \\
\hline $\mathbf{1 7}$ & $\mathrm{G} 17$ & $\mathrm{H} 17$ & $\mathrm{I} 17$ & $\mathrm{~J}$ \\
\hline $\mathbf{1 8}$ & $\mathrm{G} 18$ & $\mathrm{H} 18$ & $\mathrm{I} 18$ & $=(\mathrm{H} 18+\mathrm{H} 17) / 2^{*}(\mathrm{G} 18-\mathrm{G} 17)+\mathrm{J} 17$ \\
\hline $\mathbf{1 9}$ & $\mathrm{G} 19$ & $\mathrm{H} 19$ & $\mathrm{I} 19$ & $\mathrm{~J} 20$ \\
\hline $\mathbf{2 0}$ & $\mathrm{G} 20$ & $\mathrm{H} 20$ & $\mathrm{I} 20$ & \\
\hline
\end{tabular}

Figure 12: Scheme of the spreadsheet used to estimate the integral $\mathrm{I}\left(\mathrm{c}^{*}\right)$ in equation 10 .

In summary equation 4 can be expressed as:

$$
\tilde{\mathrm{D}}\left(\mathrm{c}^{*}\right)=-\left.\frac{1}{2 \mathrm{t}} \cdot \frac{\mathrm{dx}}{\mathrm{dc}}\right|_{\mathrm{C}^{*}} \cdot \int_{0}^{\mathrm{C}} \mathrm{xdc}=-\frac{1}{2 \mathrm{t}} \cdot \mathrm{s}\left(\mathrm{c}^{*}\right) \cdot \mathrm{I}\left(\mathrm{c}^{*}\right)
$$

In Figure 13, this equation is typed in so as to obtain the interdiffusion coefficient $\tilde{\mathrm{D}}$ in $\mathrm{cm}^{2} \cdot \mathrm{s}^{-1}$ in column $\mathrm{H}$ of the sketched spreadsheet. It is assumed that the annealing time $\mathrm{t}$ in seconds be

\begin{tabular}{|c|c|c|c|c|c|}
\hline & $\overline{\mathbf{G}}$ & $\bar{H}$ & I & $\bar{J}$ & $\bar{H}$ \\
\hline 1 & $\mathbf{C u}_{\mathrm{i}}$ & $\mathbf{X}_{i}^{\prime}$ & Derivative & Integral & Interdiff. Coefficient \\
\hline$\ldots$ & $\ldots$ & $\ldots$ & $\ldots$ & $\ldots$ & $\ldots$ \\
\hline 16 & G16 & $\mathrm{H} 16$ & I16 & J16 & $\mathrm{H} 16$ \\
\hline 17 & G17 & $\mathrm{H} 17$ & 117 & J17 & $\mathrm{H} 17$ \\
\hline 18 & G18 & $\mathrm{H} 18$ & 118 & J18 & $=-(1 / 2 / \$ T \$ 1)^{*} \mid 18^{*} \mathrm{~J} 18$ \\
\hline 19 & G19 & $\mathrm{H} 19$ & I19 & J19 & $\mathrm{H} 19$ \\
\hline 20 & G20 & $\mathrm{H} 2 \mathrm{O}$ & 120 & J20 & $\mathrm{H} 2 \mathrm{O}$ \\
\hline
\end{tabular}
stored into cell $\mathrm{T} 1$.

Figure 13: Scheme of the spreadsheet used to compute the interdiffusion coefficient $\tilde{\mathrm{D}}$ as a function of the molar concentration of $\mathrm{Cu}$. 
In Figure 14, the final results for the present analysis are plotted along with literature data by Brunel et al. $\left({ }^{8}\right)$. Additionally the end points, i. e. pure $\mathrm{Ni}$ and pure $\mathrm{Cu}$, were also included in the plot; they were calculated from values reported in the "Smithells' Metals Reference Book." ( $\left.{ }^{9}\right)$ :

$$
\begin{aligned}
\tilde{\mathrm{D}}_{\mathrm{Ni} \rightarrow \mathrm{Cu}}=1.4 \cdot e^{-\left(\frac{228,200 \mathrm{~J} / \mathrm{mol}^{-1}}{\mathrm{R} \cdot \mathrm{T}}\right)}\left[\mathrm{cm}^{2} \cdot \mathrm{s}^{-1}\right]=2.51 \cdot 10^{-10} \mathrm{~cm}^{2} \cdot \mathrm{s}^{-1} & \text { eq. } 12 \\
\text { and } \quad \tilde{\mathrm{D}}_{\mathrm{Cu} \rightarrow \mathrm{Ni}}=0.4 \cdot e^{-\left(\frac{257,900 \mathrm{~J} / \mathrm{mol}^{-1}}{\mathrm{R} \cdot \mathrm{T}}\right)}\left[\mathrm{cm}^{2} \cdot \mathrm{s}^{-1}\right]=3.87 \cdot 10^{-12} \mathrm{~cm}^{2} \cdot \mathrm{s}^{-1} & \text { eq. } 13
\end{aligned}
$$

It is apparent that the literature data falls just below the estimated curve. However, this small discrepancy only helps to corroborate the correctness of our analysis. In effect, Brunel et al. performed their experiment at $940^{\circ} \mathrm{C}$; that is $10^{\circ} \mathrm{C}$ below the annealing temperature for the present experiment. Therefore there should be expected that the assessed curve reflects higher values of $\widetilde{\mathrm{D}}$ for a slightly higher treating temperature.

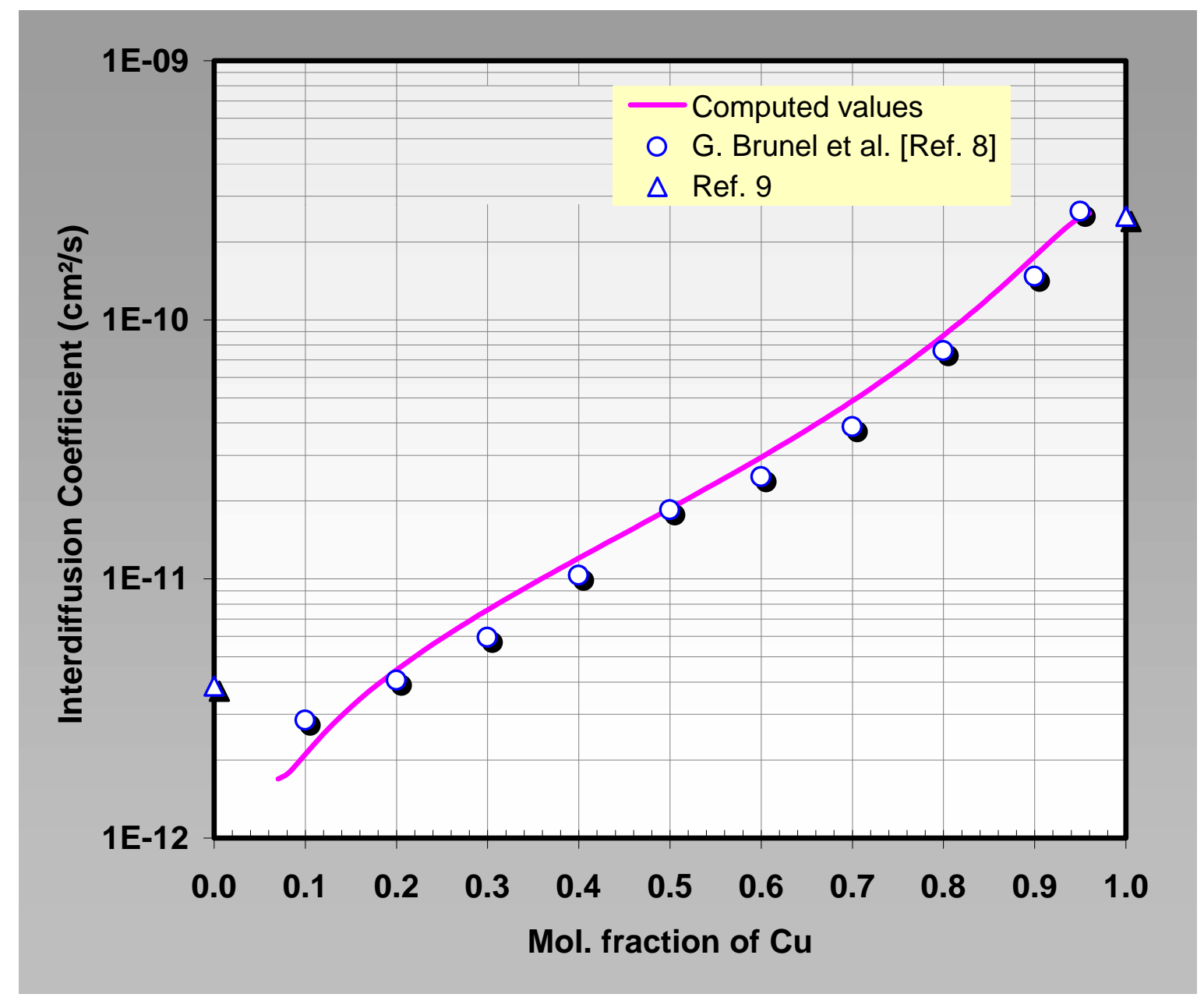

Figure 14: Final plot of the interdiffusion coefficient $\tilde{\mathrm{D}}$ as a function of copper concentration and the corresponding literature data. 


\section{Summary}

An alternative implementation of a spreadsheet to diffusion analysis has been presented. By using the Matano-Bolztmann method the students are able to investigate the dependence of the interdiffusion coefficient on the chemical composition in the $\mathrm{Cu}-\mathrm{Ni}$ binary system. This is accomplished by applying elementary numerical techniques by means of Excel ${ }^{\mathrm{TM}}$ software. Upon completing this experiment, the students are expected to fully understand the mechanics of the Darken equations and the Matano-Bolzmann method and on how to instrument mathematical tools in a commercial software in a very effortless manner. An example has provided in order to demonstrate the effectiveness of the proposed educational investigation. Finally the illustrated example results were contrasted against available data reported in the literature to demonstrate the efficacy of the students' assignment. The comparison confirmed the accuracy of the proposed method.

\section{References}

1. T. J. Jones, in "Excellence in University Teaching”, T. H. Buxton, K. W. Prichard, Ed., University of South Carolina Press, Columbia, SC, (1975): pp. 103-108.

2. P. Haasen, "Physical Metallurgy", 3rd. Edition, Cambridge University Press, Cambridge, UK, (1996): pp. 182183.

3. "Binary alloy phase diagrams", T. B. Massalski, Ed., ASM International, Materials Park, OH, (1986): pp. 942.

4. R. L. Burden and J. D. Faires, "Numerical Analysis", 5th. Ed., PWS Publishing Company, Boston, (1993): pp. 176-177.

5. S. D. Conte and C. De Boor, "Elementary Numerical Analysis; an Algorithmic Approach", 3rd. Ed., McGrawHill Book Co., NY, (1980): pp. 303-307.

6. Ibid. Ref. 4: pp. 161-162.

7. Ibid. Ref. 5: pp. 297-299.

8. G. Brunel, G. Cizeron, and P. Lacombe, Comptes Rendus Hebdomadaires des Séances de L'Académie de Sciences: C: Sciences Chimiques, 269C [16], Paris, (1969): pp. 895-898.

9. “Smithells' Metals Reference Book", 7th Ed., E. A. Brandes, G. Brook., Ed., Butterworths, London, (1992): pp. 13.79. 